\title{
Smoking is associated with pneumonia development in lung cancer patients
}

Jung Won Heo', Chang Dong Yeo', Chan Kwon Park², Sung Kyoung Kim³, Ju Sang Kim², Jin Woo Kim5, Seung Joon Kim ${ }^{6,7}$, Sang Haak Lee ${ }^{1,7}$ and Hye Seon Kang ${ }^{8^{*}}$ (D)

\begin{abstract}
Background: Various host factors can promote pneumonia susceptibility of lung cancer patients. However, data about risk factors for pneumonia in lung cancer patients receiving active treatments such as chemotherapy, radiotherapy, and surgical intervention are limited. Thus, the purpose of this study was to identify risk factors for pneumonia development in lung cancer patients.

Methods: The present study used a lung cancer cohort of the Catholic Medical Center at the Catholic University of Korea from January 2015 to December 2018. Pneumonia was defined by the presence of a new or progressive infiltration on chest imaging together with any of the following: new onset purulent sputum, change in character of chronic sputum, and fever. We ruled out noninfectious infiltration such as drug or radiation toxicity and hydrostatic pulmonary edema. We especially excluded those if computed tomography revealed sharp demarcation consolidation or ground glass opacity limited radiation field.

Results: A total of 413 patients were enrolled in this study. Pneumonia occurred in 118 (28.6\%) patients. The pneumonia group had significantly worse overall survival (OS) than the non-pneumonia group ( $456.7 \pm 35.0$ days vs. $813.4 \pm 36.1$ days, log rank $p<0.001$ ). In patients with pneumonia, OS was shorter in ex-smokers and current smokers than in never smokers ( $592.0 \pm 101.0$ days vs. $737.0 \pm 102.8$ days vs. 1357.0 days, log rank $p<0.001)$. Age (hazard ratio [HR]: 1.046; 95\% confidence interval [Cl]: 1.019-1.074; $p=0.001$ ), clinical stage IV (HR: 1.759; 95\% Cl: 1.004-3.083; $p=0.048$ ), neutropenia (HR: 2.620; 95\% Cl: 1.562-4.396; $p<0.001$ ], and smoking (HR: 2.040; 95\% Cl: $1.100-3.784 ; p=0.024$ ) were independent risk factors of pneumonia development in lung cancer patients in multivariate analysis. In subgroup analysis for patients treated with chemotherapy, age (HR: 1.043; 95\% Cl: 1.0121.074; $p=0.006$ ), neutropenia (HR: 3.199; 95\% Cl: $1.826-5.605 ; p<0.001$ ), and smoking (HR: $2.125 ; 95 \%$ Cl: $1.071-$ $4.216 ; p=0.031$ ) were independent risk factors of pneumonia development.
\end{abstract}

Conclusions: Smoking and neutropenia were risk factors affecting pneumonia development in the total group and subgroup of patients with lung cancer.

Keywords: Pneumonia, Smoking, Lung cancer

\footnotetext{
* Correspondence: ihbe3805@gmail.com

${ }^{8}$ Division of Pulmonary, Critical Care and Allergy, Department of Internal Medicine, Bucheon St. Mary's Hospital, College of Medicine, The Catholic University of Korea, 327, Sosa-ro, Bucheon-si, Gyeonggi-do 14647, Republic of Korea

Full list of author information is available at the end of the article
}

(c) The Author(s). 2020 Open Access This article is licensed under a Creative Commons Attribution 4.0 International License, which permits use, sharing, adaptation, distribution and reproduction in any medium or format, as long as you give appropriate credit to the original author(s) and the source, provide a link to the Creative Commons licence, and indicate if changes were made. The images or other third party material in this article are included in the article's Creative Commons licence, unless indicated otherwise in a credit line to the material. If material is not included in the article's Creative Commons licence and your intended use is not permitted by statutory regulation or exceeds the permitted use, you will need to obtain permission directly from the copyright holder. To view a copy of this licence, visit http://creativecommons.org/licenses/by/4.0/ The Creative Commons Public Domain Dedication waiver (http://creativecommons.org/publicdomain/zero/1.0/) applies to the data made available in this article, unless otherwise stated in a credit line to the data. 


\section{Background}

Lung cancer is the most common cause of cancer-related deaths worldwide [1]. The impact of pneumonia on cancer population is uniquely severe, accounting for more morbidity and mortality than other infectious complications [2]. Both cancer and cancer related treatments can alter immune responses of hosts. Chemotherapy-induced cytopenia, bone marrow infiltration by tumor, impaired pathogen detection, and dysregulated inflammation are host factors that can promote bacterial pneumonia susceptibility in cancer patients. Coexisting structural lung diseases such as emphysema and bronchiectasis can also affect the occurrence of pneumonia in cancer patients [3]. Further, cancer patients are more likely to be exposed to resistant bacteria because of their frequent hospital visits.

Clinical studies have identified several risk factors for postoperative pneumonia in lung cancer patients. Wellknown risk factors are as follows: old age ( $>60$ years), histopathological type of squamous cell carcinoma [4], smoking (current or previous), and the extent of excision of more than one lobe [5]. Risk factors for post bronchoscopy pneumonia in lung cancer patients are older age (> 70 years), current smoking, and central location of the tumor [6]. Previous studies have focused on pneumonia occurrence after surgery or bronchoscopy in lung cancer patients. However, data about risk factors for pneumonia in lung cancer patients receiving palliative care or active treatment including surgical intervention, chemotherapy, radiotherapy, or tyrosine kinase inhibitor (TKI) are limited. Thus, the objective of this study was to compare clinical factors between pneumonia and non-pneumonia groups and identify risk factors of pneumonia occurrence in lung cancer patients.

\section{Methods}

\section{Data source}

Seven medical centers at the Catholic University of Korea have consecutively enrolled patients with lung cancer since October 2014. The Catholic Medical Center (CMC) lung cancer registry consists of seven multicenters (Seoul St. Mary's Hospital, Yeouido St. Mary's Hospital, Eunpyeong St. Mary's Hospital, Uijeongbu St. Mary's Hospital, Bucheon St. Mary's Hospital, Incheon St. Mary's Hospital, and St. Vincent's Hospital) in the capital region of South Korea. Our lung cancer cohort enrolled lung cancer patients confirmed by tissue biopsy. We analyzed data of patients from Seoul St. Mary's Hospital and Bucheon St Mary's Hospital among cohort hospitals because their medical charts related to the development of pneumonia were available for review. CMC lung cancer registry collected smoking history including smoking status, pack-year, and duration of smoking cessation. If the patient continued smoking until diagnosis or stopped smoking within 1 month of being diagnosed with lung cancer, he or she was defined as a current smoker. Ex-smoker was defined as the patient who quitted smoking at least 1 month before the diagnosis of lung cancer. The patient who had smoked fewer than 100 cigarettes in their lifetime or had never smoked as never smoker [7]. Lung function test was performed according to the American Thoracic Society/ European Respiratory Society standardization guidelines. Clinical staging was performed using the 7th edition of TNM staging system until 2017, and that for lung cancer patients diagnosed since 2018 was based on the 8th edition of TNM staging, which was authorized by the American Joint Committee on Cancer on January 1, 2018. Patients in the first-line of therapy are those who have received one curative or palliative line of treatment. Second-line (third-line) therapy was defined as the treatment after discontinuing first-line (second-line) therapy, either for intolerance or for progressive/recurrent. In contrast, patients in the 0 line of therapy group did not receive any therapy. Clinical data including stage, pathology, treatment modality, and survival were systematically recorded by qualified data managers to improve the accuracy of data. This study was approved by the Clinical Research Ethics Committee of the Catholic Medical Center (approval number: XC140IMI0070).

\section{Pulmonary infection diagnosis criteria}

Pneumonia was defined by the presence of a new or progressive infiltration on chest radiography or computed tomography $(\mathrm{CT})$, together with any of the following: purulent sputum and fever [8]. However, differential diagnosis of pulmonary infiltration is expansive, including noninfectious mimics such as drug injury, radiation toxicity, and hydrostatic pulmonary edema [8-10]. If bacterial pneumonia is suspected, microbiological diagnosis, such as bronchoalveolar lavage or bronchial aspiration, was performed to differentiate it from radiation and cytostatic pneumonitis. However, these methods were invasive, so it was impossible to perform procedures in all patients. And the sensitivity has varied widely, ranging from 30 to $80 \%$ $[11,12]$. In patients undergoing antibiotics treatment, the sensitivity is much lower [13]. So, positive blood cultures, isolation of pathogen from sputum, transtracheal aspirate, and bronchial washing were not compulsory inclusion criteria. Especially, we excluded those when computed tomography revealed relatively sharp demarcation consolidation or ground glass opacity (GGO) with limited radiation field suggesting radiation pneumonitis. We also identified procalcitonin level. Procalcitonin is a useful marker to distinguish bacterial pneumonia from radiation pneumonitis in solid tumor patients $[14,15]$. In addition, bacterial pneumonia was diagnosed by confirming radiologic and clinical improvement after empirical antibiotics. 


\section{Data collection}

Data of basic demographics were collected, including age, gender, body mass index (BMI), smoking (current or previous smoker vs. never smoker), comorbid condition, pathologic finding (adenocarcinoma vs. squamous cell carcinoma vs. small cell lung cancer [SCLC] vs. adenosquamous cell carcinoma vs. large cell carcinoma vs. mesothelioma vs. others), line of therapy, neutropenia, pulmonary function test, the presence of endobronchial lesion in bronchoscopic finding, clinical stage (I-IV), and treatment modality (no therapy vs. surgery vs. chemotherapy vs. TKI vs. concurrent chemoradiation therapy [CCRT] vs. stereotactic body radiation therapy [SBRT] vs. radiation therapy vs. neo-adjuvant CCRT).

\section{Statistical analysis}

The Pearson's Chi-square tests and Student's $t$-test were used to compare clinical characteristics between lung cancer patients with and those without pneumonia. The survival curve according to the pneumonia development was analyzed using the Kaplan-Meier method. Hazard ratios (HRs) and corresponding 95\% confidence intervals (Cis) were calculated for predictos that were significant in multivariate Cox regression analysis. A two-sided $P$ value $<0.05$ was considered to be statistically significant. All statistical analyses were performed using SPSS for Windows software (ver. 20.0; IBM Corp., Armonk, NY, USA).

\section{Results}

A total of 413 patients diagnosed with lung cancer were included. Of these patients, 118 (28.6\%) patients developed pneumonia. Of these, 94 patients underwent CT and microorganism were detected in 42 patients. We compared clinical factors between pneumonia and nonpneumonia groups and explored clinical factors predicting pneumonia development. Mean follow-up time was $441.40 \pm 326.76$ days. Baseline characteristics of these two groups are summarized in Table 1.

In the pneumonia group, the mean age $(69.79 \pm 8.35$ vs. $66.37 \pm 10.60, p=0.002)$ and the proportion of male were higher $(83.1 \%$ vs. $69.5 \%, p=0.005)$, while the proportion of never smokers $(14.4 \%$ vs. $30.8 \%, p=0.001)$ was lower. Regarding pathological types, SCLC had higher proportion $(24.6 \%$ vs. $9.8 \%, p<0.001)$ while adenocarcinoma had lower proportion (44.9\% vs. $62.0 \%$, $p=0.002)$ in the pneumonia group. Neutropenia $(43.2 \%$ vs. $18.9 \%, p<0.001)$ was more frequently accompanied in the pneumonia group. The proportion of clinical stage III $(39.8 \%$ vs. $16.9 \%, p<0.001)$ was higher while that of clinical stage I was lower in the pneumonia group. Regarding treatment modality, chemotherapy $(39.8 \%$ vs. $25.7 \%$ ) and CCRT (14.4\% vs. 6.2\%) had higher proportions whereas surgery (22.0\% vs. $36.6 \%)$ and TKI $(5.9 \%$ vs. $16.1 \%$ ) had lower proportions in the pneumonia group (Table 1). The incidence of pneumonia occurred more frequently during treatment $(55 \%)$ or after treatment $(29.7 \%)$ than that during conservative care $(15.3 \%$, $p<0.001)$.

Patients in the pneumonia group showed a shorter median overall survival (OS) than those in the nonpneumonia group (456.7 \pm 35.0 days vs. $813.4 \pm 36.1$ days, $\log$ rank $p<0.001$ ) (Fig. 1a). Overall survival was calculated based on the date of cancer diagnosis. The total number of patients who died was 175 . Of these, 93 patients did not die at our hospital, so the cause of death was unknown. In addition, 36 patients died due to cancer-specific cause, the cancer-specific survival was $1196.2 \pm 53.9$ days in the pneumonia group and $1178.9 \pm 25.1$ days in non-pneumonia group (Log rank $=$ 0.866), with no difference between the two groups. We estimated the cumulative incidence of pneumonia cases with exposure to smoking. Those with exposure to smoking showed a higher risk of pneumonia than those without such exposure (i.e., non-smoking) (log rank $p=$ 0.0117) (Fig. 1b). Patients with smoking exposure (exsmoker or current smoker) displayed a shorter median OS than those without exposure to smoking (never smoker group) $(592.0 \pm 101.0$ days vs. $737.0 \pm 102.8$ days vs. 1357.0 days, log rank $p<0.001)$, although the difference in OS between ex-smokers and current smokers was not statistically significant (Fig. 1c).

Cox proportional hazards model revealed a 2.04-fold increased risk of pneumonia for smokers compared to non-smokers. In addition, older age (HR: 1.046; 95\% CI: $1.019-1.074 ; p=0.001$ ), advanced stage (IV) (HR: 1.759; 95\% CI: $1.004-3.083 ; p=0.048$ ), and neutropenia (HR: 2.620; 95\% CI: $1.562-4.396 ; p<0.001)$ were found to be independent risk factors for pneumonia development in lung cancer patients (Table 2).

We performed subgroup analysis for those who received treatment that included cytotoxic chemotherapy (CCRT, chemotherapy and neoadjuvant CCRT). It has been reported that they show increased risk of developing neutropenia and potentially life-threatening infection due to myelotoxic effects of chemotherapy [16]. In subgroup analysis, 285 patients were treated with therapy that included cytotoxic chemotherapy. Among them, 122 (42.8\%) patients received chemotherapy alone, 35 (12.3\%) patients received definitive CCRT, 6 (2.1\%) patients received neoadjuvant CCRT, and $3(1.1 \%)$ patients received neoadjuvant chemotherapy. Ninety-four (33.0\%) and 191 (67.0\%) patients were classified into pneumonia and nonpneumonia groups, respectively. Multivariate analysis revealed that neutropenia (HR: 3.199; 95\% CI: 1.826-5.605; $p<0.001)$ and smoking (HR: 2.125; 95\% CI: 1.071-4.216; $p=0.031$ ) were independent risk factors for pneumonia development in lung cancer patients receiving treatment that included cytotoxic chemotherapy (Table 3). 
Table 1 Comparison of baseline characteristics of lung cancer patients with or without pneumonia

\begin{tabular}{|c|c|c|c|}
\hline Characteristic & $\begin{array}{l}\text { Pneumonia } \\
(n=118)\end{array}$ & $\begin{array}{l}\text { Non-pneumonia } \\
(n=295)\end{array}$ & $p$-value \\
\hline Age, year & $69.79 \pm 8.35$ & $66.37 \pm 10.60$ & 0.002 \\
\hline Sex, male & $98(83.1)$ & 205 (69.5) & 0.005 \\
\hline $\mathrm{BMI}, \mathrm{kg} / \mathrm{m}^{2}$ & $22.80 \pm 2.943$ & $23.52 \pm 3.121$ & 0.887 \\
\hline Smoking history & & & 0.002 \\
\hline Never & $17(14.4)$ & $91(30.8)$ & 0.001 \\
\hline Former & $53(44.9)$ & $113(38.3)$ & 0.216 \\
\hline Current & $48(40.7)$ & 91 (30.8) & 0.056 \\
\hline Pack-years & $39.85 \pm 23.83$ & $39.89 \pm 25.50$ & 0.992 \\
\hline $\begin{array}{l}\text { Underlying } \\
\text { disease }\end{array}$ & $97(82.2)$ & $235(78.9)$ & 0.444 \\
\hline $\begin{array}{l}\text { Accompanied } \\
\text { cancer }\end{array}$ & $15(12.7)$ & $47(75.8)$ & 0.430 \\
\hline Pathology & & & 0.004 \\
\hline Adenocarcinoma & $53(44.9)$ & $183(62.0)$ & 0.002 \\
\hline $\mathrm{SqCC}$ & $32(27.1)$ & $64(21.7)$ & 0.238 \\
\hline $\mathrm{SCLC}$ & $29(24.6)$ & $29(9.8)$ & $<0.001$ \\
\hline Adenosquamous & $1(0.8)$ & $5(1.7)$ & 0.516 \\
\hline Large cell & $1(0.8)$ & $2(0.7)$ & 0.885 \\
\hline NOS & $0(0)$ & $1(0.3)$ & 0.527 \\
\hline Mesothelioma & $0(0)$ & $0(0)$ & \\
\hline Others & $2(1.7)$ & $8(2.7)$ & 0.354 \\
\hline Line of therapy & & & 0.067 \\
\hline 0 & $7(5.9)$ & $24(8.2)$ & \\
\hline 1 & $57(48.3)$ & $139(47.3)$ & \\
\hline 2 & $25(21.2)$ & 87 (29.6) & \\
\hline$\geq 3$ & $29(24.6)$ & $44(15.0)$ & \\
\hline Neutropenia & $51(43.2)$ & $56(18.9)$ & $<0.001$ \\
\hline \multicolumn{4}{|l|}{ PFT } \\
\hline FVC, \% pred & $82.25 \pm 16.810$ & $87.77 \pm 19.349$ & 0.218 \\
\hline $\mathrm{FEV}_{1}, \%$ pred & $78.39 \pm 19.219$ & $83.93 \pm 22.878$ & 0.083 \\
\hline $\mathrm{FEV}_{1} / \mathrm{FVC}<70 \%$ & $47(49.5)$ & $93(40.8)$ & 0.151 \\
\hline $\mathrm{FEV}_{1} / \mathrm{FVC}$ & $0.90 \pm 0.297$ & $0.93 \pm 0.259$ & 0.103 \\
\hline Clinical stage & & & $<0.001$ \\
\hline I & $15(12.7)$ & 100 (33.9) & $<0.001$ \\
\hline$\|$ & $10(8.5)$ & $19(4.6)$ & 0.476 \\
\hline III & 47 (39.8) & $50(16.9)$ & $<0.001$ \\
\hline IV & $46(39.0)$ & $124(42.0)$ & 0.534 \\
\hline Treatment modality & & & $<0.001$ \\
\hline No therapy & $7(5.9)$ & $22(7.5)$ & 0.567 \\
\hline Surgery & $26(22.0)$ & 107 (36.6) & 0.004 \\
\hline Chemotherapy & $47(39.8)$ & $75(25.7)$ & 0.005 \\
\hline TKI & $7(5.9)$ & $47(16.1)$ & 0.006 \\
\hline CCRT & $17(14.4)$ & $18(6.2)$ & 0.007 \\
\hline
\end{tabular}

Table 1 Comparison of baseline characteristics of lung cancer patients with or without pneumonia (Continued)

\begin{tabular}{llll}
\hline Characteristic & $\begin{array}{l}\text { Pneumonia } \\
(n=118)\end{array}$ & $\begin{array}{l}\text { Non-pneumonia } \\
(n=295)\end{array}$ & $p$-value \\
\hline SBRT & $0(0)$ & $2(0.7)$ & 0.367 \\
RT & $11(9.3)$ & $14(4.8)$ & 0.083 \\
Neo-adjuvant CCRT & $0(0)$ & $3(1.0)$ & 0.247 \\
\hline
\end{tabular}

Data are expressed as mean \pm standard deviation or number (\%) except where otherwise indicated

Abbreviations: BMI, body mass index; SqCC, squamous cell carcinoma; SCLC, small cell lung cancer; NOS, not otherwise specified; PFT, pulmonary function test; $\mathrm{FVC}$, forced vital capacity; pred, predictive value; $\mathrm{FEV}_{1}$, forced expiratory volume in $1 \mathrm{~s}$; TKI, tyrosine kinase inhibitor; CCRT, concurrent chemoradiation therapy; SBRT, stereotactic body radiation therapy; RT, radiation therapy

In sputum or blood culture, microorganisms were detected in $42(35.6 \%)$ of 118 pneumonia patients. Microbes were detected in $22(18.6 \%)$ patients in the blood culture test and $20(16.9 \%)$ patients in the sputum culture test. The most commonly identified bacterial species was Staphylococcus aureus $(n=13 ; 31 \%)$. Among them, methicillin-resistant Staphylococcus aureus was identified 9 times (21.4\%). The second most commonly identified bacterial species was Klebsiella pneumoniae.

\section{Discussion}

Lung cancer is a major cause of cancer-related death worldwide [1]. In immunocompromised patients, infections and pneumonia are closely related to a poor prognosis $[17,18]$. Therefore, it is important to recognize risk factors associated with pneumonia and prepare prevention strategies to reduce the occurrence of pneumonia in patients with lung cancer.

In our study, patients in the pneumonia group showed a shorter median OS than those in the non-pneumonia group. We explored clinical factors for pneumonia development in lung cancer patients. According to our research, the incidence of pneumonia was $28.6 \%$ in the lung cancer population and $33.6 \%$ in the subgroup of subjects who received therapy that included cytotoxic chemotherapy. Older age, advanced stage (IV), neutropenia, and smoking were independent risk factors for pneumonia development in lung cancer patients. Age, neutropenia, and smoking were independently associated with pneumonia development in lung cancer patients who received treatment that included cytotoxic chemotherapy.

There has been some research on risk factors for developing pneumonia in patients with lung cancer. Wang et al. [4] have demonstrated that being old aged $(>60$ years) and having squamous cell carcinoma histopathological type might be important risk factors of postoperative pneumonia in lung cancer patients after surgery. Liu et al. [5] have reported that patients with older age, smoking, and extent of excision of more than one lobe have a higher risk for pneumonia after lung cancer 


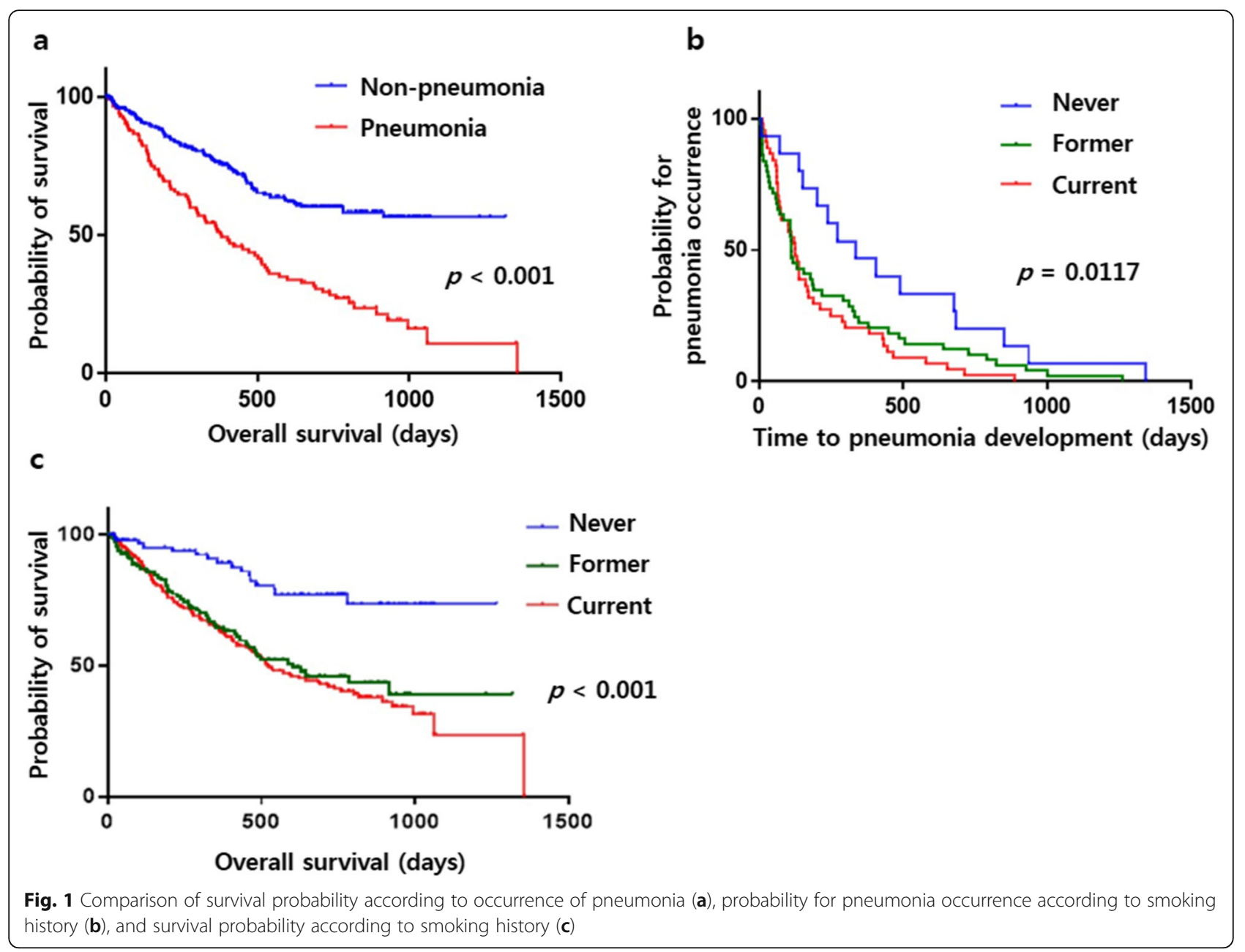

surgery. Takiguchi et al. [6] have noted that the risk factors for pneumonia after bronchoscopy are old age $(\geq$ 70 years), current smoking, and central location of the tumor. These studies were focused on pneumonia development after surgery or bronchoscopy. However, data about risk factors for pneumonia in lung cancer patients who have received active treatment such as radiation therapy and chemotherapy are limited.

Table 2 Cox multivariate proportional hazard analysis for pneumonia development in lung cancer patients

\begin{tabular}{llll}
\hline Variable & Hazard ratio & $95 \%$ Confidence interval & $p$-value \\
\hline Age & 1.046 & $1.019-1.074$ & 0.001 \\
Clinical staging & & & 0.013 \\
I & & & \\
II & 0.480 & $0.246-0.933$ & 0.030 \\
III & 1.226 & $0.512-2.937$ & 0.647 \\
IV & 1.759 & $1.004-3.083$ & 0.048 \\
Neutropenia & 2.620 & $1.562-4.396$ & $<0.001$ \\
Smoking & 2.040 & $1.100-3.784$ & 0.024 \\
\hline
\end{tabular}

Old age has been associated with pulmonary complication in many studies. Lee et al. [19] have reported that old age is associated with the development of bacterial pneumonia in patients after cytotoxic chemotherapy in advanced lung cancer patients. Age $\geq 64$ years was an independent predictors for post-operative pneumonia in lung cancer patients [5]. The elderly have several risk factors of pneumonia occurrences because of their impaired physical conditions. Dysfunction of the immune

Table 3 Cox multivariate proportional hazard analysis for pneumonia development in lung cancer patients who received treatment including cytotoxic chemotherapy

\begin{tabular}{clll}
\hline & Hazard ratio & $95 \%$ Confidence interval & $p$-value \\
\hline Age & 1.043 & $1.012-1.074$ & 0.006 \\
Line of therapy & & & 0.015 \\
1 & & & \\
2 & 0.405 & $0.212-0.775$ & 0.006 \\
$\geq 3$ & 0.904 & $0.463-1.763$ & 0.767 \\
Neutropenia & 3.199 & $1.826-5.605$ & $<0.001$ \\
Smoking & 2.125 & $1.071-4.216$ & 0.031 \\
\hline
\end{tabular}


system is one important cause of pneumonia. Aspirated oropharyngeal secretions into the lung can induce aspiration pneumonia due to swallowing difficulties in old patients [20].

Among risk factors for cancer treatment related pneumonia, neutropenia is one of the most well-known factors. Neutrophils are sensitive to alkylating agents and nucleoside analogs. Absolute neutrophil count decreases with increasing dose of cytotoxic chemoagents [8]. Severe neutropenia defined as a count $\leq 500 / \mu \mathrm{L}$ is associated with increased severe lung infections caused by bacterial and fungus [21]. Neutropenic pneumonia is affected by rapid onset, duration, severity, and underlying physiologic process [22-24]. Lung cancer is a solid cancer known to be associated with better prognosis in febrile neutropenic patients compared to other hematologic malignancies [25]. However, lung cancer patients might have smoking and age-related comorbidities such as chronic obstructive pulmonary disease and interstitial lung diseases in which Pseudomonas aeruginosa is frequently present. Old age is associated with high mortality in lung cancer patients with febrile neutropenia, although the risk of lung cancer is low in neutropenic patients [26].

In our study, smoking was a common risk factor for pneumonia development in total lung cancer patients and patients who received treatment that included cytotoxic chemotherapy. Smoking is known to be associated with lower-socioeconomic status, poor diet, increased alcohol consumption, and reduced physical activity. The relationship between smoking and community acquired pneumonia has been reported [27]. Smoking affects the loss of cilia, inhibits alveolar macrophage function, mucous gland hypertrophy, and increases goblet cells. This causes microbes to be present and widespread in the bronchus. Oxidative stress and cytokine release are triggered, leading to immune response. This makes the bronchial mucosal epithelium more inflammatory and susceptible to infection [28]. Nicotine can suppress natural killer (NK) cell activity. NK cells are usually activated immune response against viral infections [29-31]. Agostini et al. [16] have noted that smoking increases postoperative pulmonary complications such as increased hospital mortality, intensive care unit admission rate, and hospital length of stay. Jung et al. [32] have also shown that smoking is one of independent risk factors for the development of post-operative pneumonia in cancer patients. Smoking cessation before surgery can reduce postoperative complications [33]. The difference in pneumonia occurrence between current smokers and ex-smokers was not apparent in our study. Further studies are needed to clarify effects of smoking cessation duration before treatment in lung cancer patients.

In advanced stage cancer patients, infection occurs more easily due to bronchial permeability disorders as pressure on the bronchial walls increases caused by enlargement of tumor mass or lymph nodes [21]. In addition, cancer metastasis to the bone marrow can cause leukopenia and anemia [34]. Moreover, cough reflex impairment might be triggered by narcotics, psychotropic therapy, or metastases to the brain [35]. Cancer related treatments can cause pneumonia development in patients with advanced staged lung cancer. Most drugs used for chemotherapy suppress the function of the immune system. Alkalizing drugs, antimetabolites of purines, pyrimidines, and folic acid all have immunosuppressive effect [36]. In our study, advanced staging was associated with pneumonia development in lung cancer patients.

There was a difference in the occurrence of pneumonia according to the pathologic type. Squamous cell carcinomas are much more commonly endobronchial lesions protruding into and obstructing large central bronchus, while adenocarcinomas are much more commonly peripheral [37]. Thus, post-obstructive pneumonia occurs frequently in squamous cell carcinoma. SCLC is strongly associated with smoking. Most SCLC patients receive treatment based on cytotoxic chemotherapy and/ or radiotherapy. They are vulnerable to infections due to suppressed cellular immunity [38].

This study has some limitations. First, it was a retrospective study. Nonetheless, our study included patients from multiple centers with a large sample size. Second, our study did not investigate whether pneumococcal vaccine (PSV 23 or PCV 13) was given. Chiou et al. [39] noted that the cumulative hospitalization rate for pneumonia over 2 years in lung cancer patients was $37.1 \%$ in the vaccinated group and $55.4 \%$ in the non-vaccinated group. Third, exclusion of radiation pneumonitis was not complete because differential diagnosis between pneumonia and radiation pneumonia was based on retrospective medical chart and radiologic findings reviews. However, we tried to exclude cases suggesting radiation pneumonitis such as those with relatively sharp demarcation consolidation or GGO with limited radiation field as much as possible.

Despite these limitations, the present study had several strengths. This study was a 7 multi-center study with a large sample size. To identify the risk factors for pneumonia development in patients with lung cancer, pneumonia patients were compared with a relatively large number of non-pneumonia patients. In addition, when the patients were newly diagnosed with lung cancer, data was collected prospectively after registration and the bias was minimized.

\section{Conclusion}

In conclusion, old age, smoking, and neutropenia were common risk factors for pneumonia development in 
total patients with lung cancer and patients who received treatment that included chemotherapy. Thus, cautious monitoring of elderly patients, especially those who receive cytotoxic chemotherapy or have a history of smoking, is important. Future studies are needed to clarify effects of smoking cessation before treatment on pneumonia development in lung cancer patients.

\section{Abbreviations}

TKI: Tyrosine kinase inhibitor; CMC: Catholic Medical Center; BMI: Body mass index; SCLC: Small cell lung cancer; SBRT: Stereotactic body radiation therapy; CCRT: Concurrent chemoradiation therapy; GGO: Ground glass opacity; HRs: Hazard ratios; Cls: Confidence intervals; OS: Overall survival; NK: Natural killer; PSV: Pneumococcal polysaccharide vaccine; PCV: Pneumococcal conjugate vaccine

\section{Acknowledgements}

Not applicable.

\section{Authors' contributions}

JWH, JWK, CDY, SHL, and HSK contributed to the conception and design of the study, data analysis and interpretation, and the drafting and substantial revision of this manuscript. CKP, SKK, JSK, JWK, SJK, and SHL contributed to the acquisition of data. CDY, JWK, and HSK revised the manuscript. The authors read and approved the final manuscript.

\section{Funding}

None.

\section{Availability of data and materials}

Data analyzed in the current study are not publicly available. They may be made available from the corresponding authors upon reasonable request.

\section{Ethics approval and consent to participate}

This study was approved by the Clinical Research Ethics Committee of the Catholic Medical Center (approval number: XC140IMI0070).

\section{Consent for publication}

Not applicable.

\section{Competing interests}

The authors declare that they have no competing interests.

\footnotetext{
Author details

'Division of Pulmonary, Critical Care and Sleep Medicine, Department of Internal Medicine, Eunpyeong St. Mary's Hospital, College of Medicine, The Catholic University of Korea, Seoul, Republic of Korea. ${ }^{2}$ Division of Pulmonary, Critical Care and Allergy, Department of Internal Medicine, Yeouido St. Mary's Hospital, College of Medicine, The Catholic University of Korea, Seoul, Republic of Korea. ${ }^{3}$ Division of Pulmonary, Critical Care and Allergy, Department of Internal Medicine, St. Vincent's Hospital, College of Medicine, The Catholic University of Korea, Seoul, Republic of Korea. ${ }^{4}$ Division of Pulmonary, Critical Care and Sleep Allergy, Department of Internal Medicine, Incheon St. Mary's Hospital, College of Medicine, The Catholic University of Korea, Seoul, Republic of Korea. ${ }^{5}$ Division of Pulmonary, Critical Care and Sleep Medicine, Department of Internal Medicine, Uijeongbu St. Mary's Hospital, College of Medicine, The Catholic University of Korea, Seoul, Republic of Korea. ${ }^{6}$ Division of Pulmonary, Critical Care and Allergy, Department of Internal Medicine, Seoul St. Mary's Hospital, College of Medicine, The Catholic University of Korea, Seoul, Republic of Korea. ${ }^{7}$ Cancer Research Institute, College of Medicine, The Catholic University of Korea, Seoul, Republic of Korea. ${ }^{8}$ Division of Pulmonary, Critical Care and Allergy, Department of Internal Medicine, Bucheon St. Mary's Hospital, College of Medicine, The Catholic University of Korea, 327, Sosa-ro, Bucheon-si, Gyeonggi-do 14647, Republic of Korea.
}

Received: 13 December 2019 Accepted: 20 April 2020

Published online: 01 May 2020

\section{References}

1. Bray F, Ferlay J, Soerjomataram I, Siegel RL, Torre LA, Jemal A. Global cancer statistics 2018: GLOBOCAN estimates of incidence and mortality worldwide for 36 cancers in 185 countries. CA Cancer J Clin. 2018:68(6):394-424.

2. Safdar A, Armstrong D. Infectious morbidity in critically ill patients with cancer. Crit Care Clin. 2001;17(3):531-70.

3. Wong JL, Evans SE. Bacterial pneumonia in patients with cancer: novel risk factors and management. Clin Chest Med. 2017;38(2):263-77.

4. Wang Z, Cai XJ, Shi L, Li FY, Lin NM. Risk factors of postoperative nosocomial pneumonia in stage I-Illa lung cancer patients. Asian Pac J Cancer Prev. 2014;15(7):3071-4

5. Liu GW, Sui XZ, Wang SD, Zhao H, Wang J. Identifying patients at higher risk of pneumonia after lung resection. J Thorac Dis. 2017;9(5):1289-94.

6. Takiguchi H, Hayama N, Oguma T, Harada K, Sato M, Horio Y, et al. Postbronchoscopy pneumonia in patients suffering from lung cancer: development and validation of a risk prediction score. Respir Investig. 2017; 55(3):212-8.

7. Ban WH, Lee JM, Ha JH, Yeo CD, Kang HH, Rhee CK, et al. Dyspnea as a prognostic factor in patients with non-small cell lung cancer. Yonsei Med J. 2016;57(5):1063-9

8. Evans SE, Ost DE. Pneumonia in the neutropenic cancer patient. Curr Opin Pulm Med. 2015;21(3):260-71

9. Klastersky J, Aoun M. Opportunistic infections in patients with cancer. Ann Oncol. 2004;15(Suppl 4):iv329-35.

10. Peckham D, Elliott MW. Pulmonary infiltrates in the immunocompromised: diagnosis and management. Thorax. 2002;57(Suppl 2):ii3-7.

11. Kottmann RM, Kelly J, Lyda E, Gurell M, Stalica J, Ornisby W, et al. Bronchoscopy with bronchial lavage: determinants of yield and impact on management in immunosuppressed patients. Thorax. 2011;66:823.

12. Hummel M, Rudert S, Hof H, Hehlmann R, Buchheidt D. Diagnostic yield of bronchosopy with bronchoalveolar lavage in febrile patients with hematologic malignancies and pulmonary infiltrates. Ann Hematol. 2008;87: 291-7.

13. Kim ES, Kim E-C, Lee S-M, Yang S-C, Yoo C-G, Kim YW, et al. Bacterial yield from quantitative cultures of bronchoalveolar lavage fluid in patients with pneumonia on antimicrobial therapy. Korean J Intern Med. 2012;27:156-62.

14. Vincenzi B, Fioroni I, Pantano F, Angeletti S, Dicuonzo G, Zoccoli A, et al. Procalcitonin as diagnostic marker of infection in solid tumors patients with fever. Sci Rep. 2016;17(6):28090.

15. Wang Z, Huo B, Wu Q, Dong L, Fu H, Wang S, et al. The role of procalcitonin in differential diagnosis between acute radiation pneumonitis and bacterial pneumonia in lung cancer patients receiving thoracic radiotherapy. Sci Rep. 2020;19;10(1):2941.

16. Agostini P, Cieslik H, Rathinam S, Bishay E, Kalkat MS, Rajesh PB, et al. Postoperative pulmonary complications following thoracic surgery: are there any modifiable risk factors? Thorax. 2010;65(9):815-8.

17. Azoulay E, Lemiale V, Mokart D, Pene F, Kouatchet A, Perez P, et al. Acute respiratory distress syndrome in patients with malignancies. Intensive Care Med. 2014;40(8):1106-14.

18. Lee EH, Kim EY, Lee SH, Chang J, Park MS. Risk factors and clinical characteristics of pneumocystis jirovecii pneumonia in lung cancer. Sci Rep. 2019;9:2094

19. Lee JO, Kim DY, Lim JH, Seo MD, Yi HG, Kim YJ, et al. Risk factors for bacterial pneumonia after cytotoxic chemotherapy in advanced lung cancer patients. Lung Cancer. 2008;62(3):381-4.

20. Akinosoglou KS, Karkoulias K, Marangos M. Infectious complications in patients with lung cancer. Eur Rev Med Pharmacol Sci. 2013;17(1):8-18.

21. Bodey GP, Buckley M, Sathe YS, Freireich EJ. Quantitative relationships between circulating leukocytes and infection in patients with acute leukemia. Ann Intern Med. 1966;64(2):328-40.

22. Kuderer NM, Dale DC, Crawford J, Cosler LE, Lyman GH. Mortality, morbidity, and cost associated with febrile neutropenia in adult cancer patients. Cancer. 2006;106(10):2258-66.

23. Sharma A, Lokeshwar N. Febrile neutropenia in haematological malignancies. J Postgrad Med. 2005:51(Suppl 1):S42-8.

24. Freifeld AG, Bow EJ, Sepkowitz KA, Boeckh MJ, Ito Jl, Mullen CA, et al. Clinical practice guideline for the use of antimicrobial agents in neutropenic 
patients with cancer: 2010 update by the infectious diseases society of America. Clin Infect Dis. 2011;52(4):e56-93.

25. Klastersky J, Paesmans M, Rubenstein EB, Boyer M, Elting L, Feld R, et al. The multinational Association for Supportive Care in cancer risk index: a multinational scoring system for identifying low-risk febrile neutropenic cancer patients. J Clin Oncol. 2000;18(16):3038-51.

26. Lanoix JP, Pluquet E, Lescure FX, Bentayeb H, Lecuyer E, Boutemy $M$, et al. Bacterial infection profiles in lung cancer patients with febrile neutropenia. BMC Infect Dis. 2011;11:183.

27. Almirall J, Bolibar I, Serra-Prat M, Roig J, Hospital I, Carandell E, et al. New evidence of risk factors for community-acquired pneumonia: a populationbased study. Eur Respir J. 2008;31(6):1274-84.

28. Arnson Y, Shoenfeld Y, Amital H. Effects of tobacco smoke on immunity, inflammation and autoimmunity. J Autoimmun. 2010;34(3):J258-65.

29. Brandstadter JD, Yang Y. Natural killer cell responses to viral infection. J Innate Immun. 2011;3(3):274-9.

30. Stemmelin GR, Doti CA, Shanley CM, Ceresetto JM, Rabinovich OM, Vicente Reparaz MA, et al. Smoking as a cause for mild chronic neutrophilia. Blood. 2004;104(11):3796

31. Hsieh MM, Everhart JE, Byrd-Holt DD, Tisdale JF, Rodgers GP. Prevalence of neutropenia in the U.S. population: age, sex, smoking status, and ethnic differences. Ann Intern Med. 2007:146(7):486-92.

32. Jung J, Moon SM, Jang $\mathrm{HC}$, Kang $\mathrm{Cl}$, Jun JB, Cho YK, et al. Incidence and risk factors of postoperative pneumonia following cancer surgery in adult patients with selected solid cancer: results of "cancer POP" study. Cancer Med. 2018;7(1):261-9.

33. Lugg ST, Tikka T, Agostini PJ, Kerr A, Adams K, Kalkat MS, et al. Smoking and timing of cessation on postoperative pulmonary complications after curative-intent lung cancer surgery. J Cardiothorac Surg. 2017;12(1):52.

34. Ali MA, Kraut MJ, Valdivieso M, Herskovic AM, Du W, Kalemkerian GP. Phase II study of hyperfractionated radiotherapy and concurrent weekly alternating chemotherapy in limited-stage small cell lung cancer. Lung Cancer. 1998;22(1):39-44

35. Law A, Karp DD, Dipetrillo T, Daly BT. Emergence of increased cerebral metastasis after high-dose preoperative radiotherapy with chemotherapy in patients with locally advanced nonsmall cell lung carcinoma. Cancer. 2001; 92(1):160-4.

36. van Meerten E, Verweij J, Schellens JH. Antineoplastic agents. Drug interactions of clinical significance. Drug Saf. 1995;12(3):168-82.

37. $E G, O T, T Y, M M, H I, K T$, et al. Obstructive pneumonitis in lung cancer patients-a retrospective study. Nihon Kyobu Shikkan Gakkai Zasshi. 1992; 30(10):1820-4

38. Maschmeyer G, Link H, Hiddemann W, Meyer P, Helmerking M, Eisenmann

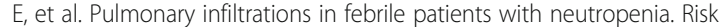
factors and outcome under empirical antimicrobial therapy in a randomized multicenter study. Cancer. 1994;73(9):2296-304.

39. Chiou WY, Hung SK, Lai CL, Lin HY, Su YC, Chen YC, et al. Effect of 23-valent pneumococcal polysaccharide vaccine inoculated during anti-cancer treatment period in elderly lung cancer patients on community-acquired pneumonia hospitalization: a Nationwide population-based cohort study. Medicine (Baltimore). 2015;94(26):e1022.

\section{Publisher's Note}

Springer Nature remains neutral with regard to jurisdictional claims in published maps and institutional affiliations.

Ready to submit your research? Choose BMC and benefit from:

- fast, convenient online submission

- thorough peer review by experienced researchers in your field

- rapid publication on acceptance

- support for research data, including large and complex data types

- gold Open Access which fosters wider collaboration and increased citations

- maximum visibility for your research: over $100 \mathrm{M}$ website views per year

At BMC, research is always in progress.

Learn more biomedcentral.com/submissions 